\title{
Activation of Metabotropic Glutamate Receptors Produces Reciprocal Regulation of lonotropic Glutamate and GABA Responses in the Nucleus of the Tractus Solitarius of the Rat
}

\author{
Steven R. Glaum and Richard J. Miller \\ Department of Pharmacological and Physiological Sciences, The University of Chicago, Chicago, Illinois 60637
}

Whole-cell voltage-clamp recordings were made in thin transverse slices from neurons of the dorsomedial subdivision of the nucleus of the tractus solitarius (NTS) of the rat. Cells were exposed to either the ionotropic glutamate receptor agonist $(R, S)-\alpha$-amino-3-hydroxy-5-methylisoxazole-4-propionate (AMPA) or the $\mathrm{GABA}_{\mathrm{A}}$ receptor agonist muscimol via pressure ejection directed at the cell soma. The metabotropic glutamate receptor agonist 1S,3R-1-aminocyclopentane-1,3-dicarboxylate (1S,3R-ACPD; 2-100 $\mu \mathrm{M}$ ) reversibly depressed muscimol-evoked currents. Conversely, 1 S,3R-ACPD reversibly potentiated AMPA-evoked currents. High-frequency stimulation of the tractus solitarius in the presence of 6,7-dinitroquinoxaline-2,3-dione and D-2-amino5-phosphonopentanoic acid also produced a reversible depression of muscimol-evoked currents that was occluded in the presence of $100 \mu \mathrm{M} \mathrm{1S,3R-ACPD.} \mathrm{8-Br-cGMP} \mathrm{or} \mathrm{brain-}$ derived natriuretic peptide mimicked the effects of $1 S, 3 R$ ACPD on AMPA and muscimol currents. However, agents that mimicked the actions of CAMP or diacylglycerol did not. These findings indicate that metabotropic glutamate receptors may mediate multiple components of excitatory transmission in the NTS including modulation of glutamate and GABA-activated ion channels.

[Key words: cardiovascular, medulla, solitary tract, baroreceptor, 1S,3R-ACPD, patch clamp]

Recent evidence has indicated that stimulation of metabotropic glutamate receptors within the nucleus of the tractus solitarius (NTS) mimics the effects of baroreceptor activation in vivo (Pawlowski-Dahm and Gordon, 1992). We have demonstrated that activation of metabotropic glutamate receptors within the dorsomedial subdivision of the NTS, a principle region for the termination of baroreceptor afferents, produces a variety of cellular effects (Glaum and Miller, 1992; Glaum et al., 1993). 1S,3R1-aminocyclopentane-1,3-dicarboxylate (1S,3R-ACPD), a selective agonist at metabotropic glutamate receptors, depolarized some NTS neurons due to the closure of a $\mathrm{K}^{+}$channel. This

\footnotetext{
Received July 10, 1992; revised Sept. 14, 1992; accepted Oct. 16, 1992

S.R.G. was supported by National Institutes of Health T32HL7237-14. Additional support came from the Brain Research Foundation, Digestive Disease Care Center Award 1P30DK42086-01, and U.S. Public Health Service Grants DA-02575, DA-02121, and MH-40165 to R.J.M.

Correspondence should be addressed to Steven R. Glaum, Ph.D., Department of Pharmacological and Physiological Sciences, The University of Chicago, 947 East 58th Street, Chicago, IL 60637.

Copyright (C) 1993 Society for Neuroscience $0270-6474 / 93 / 131636-06 \$ 05.00 / 0$
}

effect was found to be independent of changes in $\left[\mathrm{Ca}^{2+}\right]_{i}$ and could be mimicked by endogenous glutamate released from afferent projections to the NTS by high-frequency stimulation of the tractus solitarius (TS). Furthermore, $1 S, 3 R$-ACPD reduced the glutamatergic EPSC and GABAergic IPSC evoked by lowfrequency stimulation in the region of the TS. These effects support the view that the action of glutamate at mctabotropic receptors plays a key role in synaptic transmission from baroreceptor afferents (Leone and Gordon, 1989; Meeley et al., 1989; Drewe et al., 1990; Mifflin and Felder, 1990).

In our previous report, we suggested that the ability of $1 S, 3 R$ ACPD to inhibit synaptic transmission in the NTS might be due to a reduction in the presynaptic release of glutamate and GABA. However, in the present investigation we have identified additional postsynaptic effects of $1 S, 3 R$-ACPD-an inhibitory action on postsynaptic $\mathrm{GABA}_{\mathrm{A}}$ responses and a simultaneous potentiation of postsynaptic $(R, S)$ - $\alpha$-amino-3-hydroxy-5-methylisoxazole-4-propionate (AMPA)-activated currents. These results help to explain the potent reduction of inhibitory transmission by $1 S, 3 R$-ACPD and also provide another example of the multifaceted signal transduction mechanisms linked to the activation of metabotropic glutamate receptors (Miller, 1991).

\section{Materials and Methods}

Preparation of slices and recordings were made as previously described (Glaum and Miller, 1992). Briefly, Sprague-Dawley rats of either sex, aged between 18 and $36 \mathrm{~d}$, were given overdoses of ether and the whole brains, including the cervical spinal cord, were rapidly removed and placed in ice-cold artificial cerebrospinal fluid (aCSF), which contained (in $\mathrm{mM}$ ) $\mathrm{NaCl}, 126 ; \mathrm{NaHCO}_{3}, 26.2 ; \mathrm{NaH}_{2} \mathrm{PO}_{4}, 1 ; \mathrm{KCl}, 3 ; \mathrm{MgSO}_{4}, 1.5$; $\mathrm{CaCl}_{2}, 2.5$; and glucose, 10 . Transverse $250 \mu \mathrm{m}$ brainstem slices containing the NTS were prepared and submerged in a recording chamber where they were continuously perfused $\left(4-5 \mathrm{ml} \cdot \mathrm{min}^{-1}\right)$ with oxygenated aCSF at room temperature.

Whole-cell recordings were obtained from 63 visually identified neurons in the dorsomedial subdivision of the NTS adjacent to the area postrema. Patch electrodes were filled with a solution containing (in mм) $\mathrm{K}^{+}$-gluconate, $145 ; \mathrm{MgCl}_{2}, 2$; HEPES, 5; EGTA, 1.1; $\mathrm{CaCl}_{2}, 0.1$; and $\mathrm{K}_{2} \mathrm{ATP}, 5$. Where indicated, GTP- $\gamma$-S was dissolved in the intracellular solution to a final concentration of $400 \mu \mathrm{M}$ and used within 1 $\mathrm{hr}$ for recording. Neurons were voltage clamped at $V_{\text {hold }}=-50 \mathrm{mV}$. A single experiment was performed in each slice. AMPA or muscimol (10 $\mu \mathrm{M})$ was applied by a brief $(20-45 \mathrm{msec})$ pressure pulse $(2-10 \mathrm{psi})$ via a blunt patch pipette (approximate tip diameter, $5 \mu \mathrm{m}$ ) directed toward the soma under visual guidance. Recordings were obtained in the presence of D-2-amino-5-phosphonopentanoic acid (AP5; $50 \mu \mathrm{M}$ ) and either bicuculline $(10 \mu \mathrm{M})$ or 6,7-dinitroquinoxaline-2,3-dione (DNQX; 10 $\mu \mathrm{M}$ ), respectively. Tetrodotoxin (TTX; $0.5 \mu \mathrm{M}$ ) was included in all experiments examining $I_{\mathrm{AMPA}}$ and where indicated in experiments examining the muscimol-activated current $\left(I_{\text {MUsc }}\right)$. The absence of pressure ejection artifacts was confirmed at the conclusion of the experiments by the addition of the remaining antagonist (DNQX or bicuculline). 


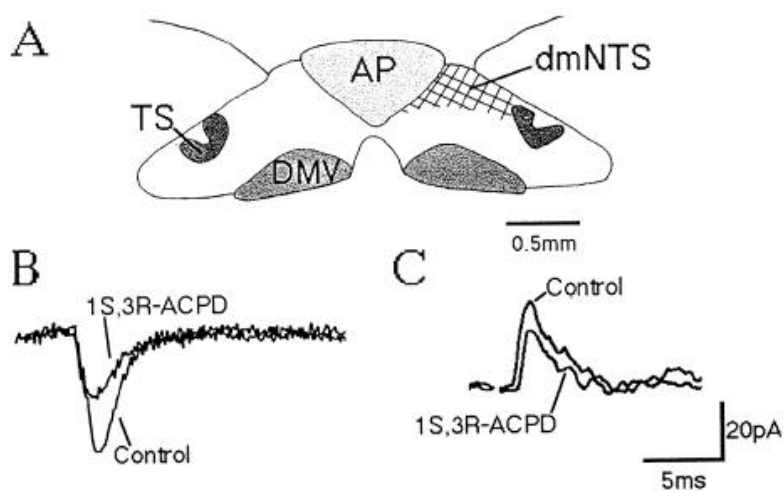

Figure 1. Excitatory and inhibitory transmission were inhibited by $1 S, 3 R$-ACPD in the dorsomedial NTS. $A$, Transverse schematic of the NTS at the level of the area postrema $(A P)$ shows the dorsomedial subnucleus ( $d m N T S)$ where recordings were made. Also shown is the dorsal motor nucleus of the vagus $(D M V)$. Electrical stimulation in the region of the TS evoked a monosynaptic EPSC in the presence of bicuculline $(10 \mu \mathrm{M})$ and AP5 $(50 \mu \mathrm{M})$. In the presence of DNQX $(10 \mu \mathrm{M})$ and AP5 $(50 \mu \mathrm{M})$, a monosynaptic IPSC is recorded in the majority of neurons in this region (see Glaum and Miller, 1992). B. The metabotropic agonist $1 S, 3 R$-ACPD $(50 \mu \mathrm{M})$ inhibited the evoked EPSC ( $V_{\text {hold }}$ $=-80 \mathrm{mV}) . C$, The monosynaptic IPSC was similarly inhibited by $1 S, 3 R-A C P D(50 \mu \mathrm{M})\left(V_{\text {hold }}=-50 \mathrm{mV}\right)$.

$1 S, 3 R$-ACPD $(2-100 \mu \mathrm{M})$ was delivered in the perfusate for $0.5-4 \mathrm{~min}$. In 14 experiments, cells were also exposed to 8 -Br-cGMP $(100 \mu \mathrm{M})$, delivered in the perfusate for $2-4 \mathrm{~min}$. In nine occlusion experiments, control responses for $1 S, 3 R$-ACPD $(100 \mu \mathrm{M}, 1-4 \mathrm{~min})$ and 8-Br-cGMP (2-4 min) were determined prior to the combined application of drugs applied for the control intervals. All other drugs were delivered in the perfusate for the indicated intervals. In all cases, the flow rate of the perfusate was carefully regulated to avoid artifactual changes in the amplitudes of the AMPA and muscimol currents.

High-frequency stimulation was carried out by placing a bipolar tungsten stimulating electrode in the region of the ipsilateral tractus solitarius (TS), as previously described (Glaum and Miller, 1992). Recordings of muscimol currents were made as described above, but in the absence of TTX. Single stimulus trains $(50 \mathrm{~Hz}, 100-300 \mathrm{msec}, 3.0-5.2 \mathrm{~V})$ were delivered 5-10 sec prior to the application of muscimol. The effects of stimulation and $100 \mu \mathrm{M} 1 S, 3 R$-ACPD (1-3 min) on $I_{\text {Musc }}$ were examined independently in seven cells. The effects of stimulation in the presence of $1 S, 3 R$-ACPD were examined in six of these cells.

Data were filtered at $3 \mathrm{kHz}$ and stored on a chart recorder (Gould), digitized at $125 \mathrm{kHz}$ by a computer-driven analog-to-digital converter (INDEC Systems), and stored on hard disk for subsequent analysis.

The peak amplitudes of $I_{\text {MUSC }}$ and $I_{\text {AMPA }}$ were evaluated immediately prior to the addition of drugs $\left(I_{\text {control }}\right)$ and compared to the current at the end of the drug application $\left(I_{\text {treatment }}\right)$. The effect of high-frequency stimulation on $I_{\text {MusC }}$ was evaluated immediately following the stimulus. Data were normalized to the control value and expressed as $\left(I_{\text {treatment }} /\right.$ $\left.I_{\text {control }}\right) * 100$. Values were then pooled and expressed as the mean \pm SEM.

\section{Results}

Previous investigations (Champagnat et al., 1985; Donoghue et al., 1985; Miles, 1987; Brooks et al., 1992; Glaum and Miller, 1992) have shown that a single low-intensity stimulus in the region of the TS produces a monosynaptic DNQX-sensitive EPSC and, in many NTS neurons, a mixed mono- and polysynaptically evoked bicuculline-sensitive IPSC. Figure 1 shows the region of the NTS examined in both our previous (Glaum and Miller, 1992; Glaum et al., 1993) and present studies. Figure 1 also illustrates the inhibitory effects of $50 \mu \mathrm{M} 1 S, 3 R$ ACPD on the monosynaptic EPSC and IPSC recorded from these neurons following TS stimulation (see also Glaum and Miller, 1992).
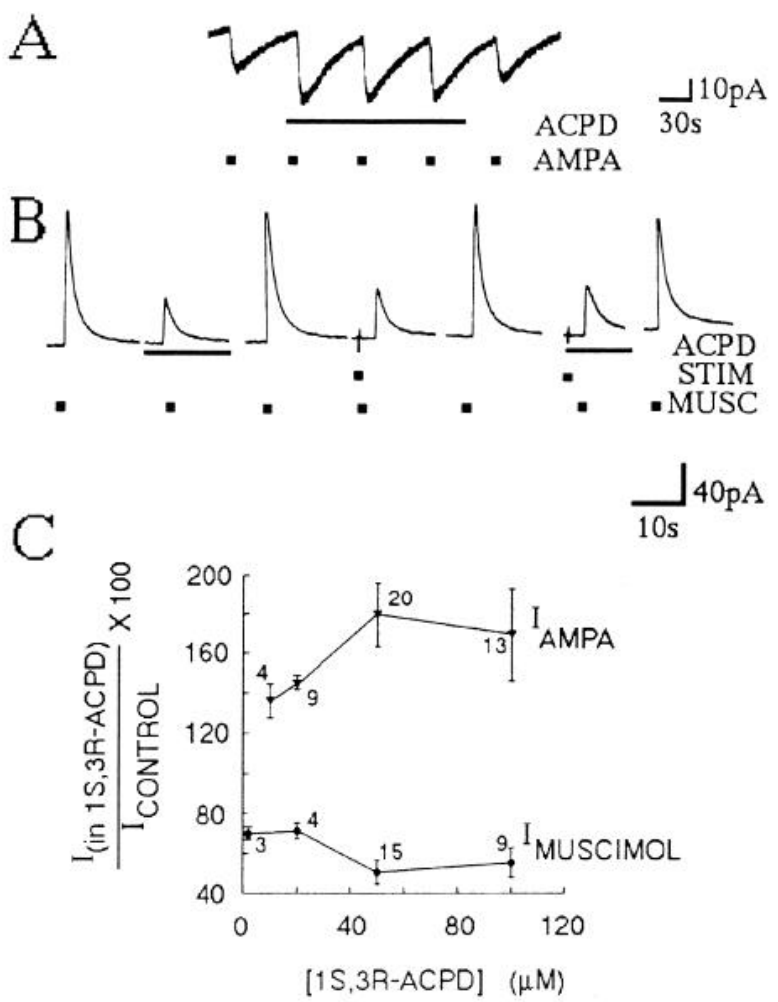

Figure 2. 1S,3R-ACPD reversibly potentiated AMPA-evoked currents and reversibly inhibited muscimol currents. $A$, AMPA currents evoked by brief pressure ejection of AMPA onto neurons in the dorsomedial NTS were potentiated in the presence of $1 S, 3 R$-ACPD ( $A C P D$; $10 \mu \mathrm{M})$. AMPA currents were evoked from $V_{\text {hold }}=-50 \mathrm{mV}$ in the presence of TTX $(0.5 \mu \mathrm{M})$, AP5 $(50 \mu \mathrm{M})$, and bicuculline $(10 \mu \mathrm{M})$ in this and all subsequent figures. $B$, The outward current evoked by pressureapplied muscimol (MUSC) was reversibly inhibited in the presence of $1 S, 3 R$-ACPD $(A C P D ; 100 \mu \mathrm{M})$ or by $50 \mathrm{~Hz}(100 \mathrm{msec}, 4.3 \mathrm{~V})$ stimulation in the region of the TS $(S T I M)$. An identical stimulation in the presence of $1 S, 3 R$-ACPD produced no further inhibition of the muscimol current. Recording was made from $V_{\text {hold }}=-50 \mathrm{mV}$ in the presence of DNQX $(10 \mu \mathrm{M})$ and AP5 $(50 \mu \mathrm{M})$ in this and all subsequent figures. $C$, Dose-response relationship for the effects of $1 S, 3 R$-ACPD on AMPA $\left(I_{A M P A}\right)$ and muscimol $\left(I_{M U S C I M O L}\right)$ currents in the NTS. Values shown are mean \pm SEM for three or more cells, as indicated.

In order to examine the possible contribution of postsynaptic actions of $1 S, 3 R$-ACPD on this inhibition of afferent synaptic transmission in the NTS, neurons were exposed to brief pressure pulses of selective agonists at ionotropic glutamate and $\mathrm{GABA}_{\mathrm{A}}$ receptors. Figure $2 A$ illustrates the response to pressure-applied AMPA in a single NTS neuron in the absence and presence of $1 S, 3 R$-ACPD $(10 \mu \mathrm{M}) .1 S, 3 R$-ACPD produced a rapid and reversible potentiation of the AMPA current $\left(I_{\mathrm{AMPA}}\right)$. Maximum potentiation of $I_{\mathrm{AMPA}}$ was observed within $1 \mathrm{~min}$ of $1 S, 3 R$ ACPD application, and this effect was not diminished in the continuous presence of $1 S, 3 R$-ACPD. $I_{\mathrm{AMPA}}$ was observed to recover to control values rapidly (1-2 $\mathrm{min}$ ) upon washout of $1 S, 3 R$-ACPD. Curiously, AMPA currents evoked following washout of $1 S, 3 R$-ACPD were sometimes transiently smaller than the control value. The effects of $1 S, 3 R$-ACPD on $I_{\text {AMPA }}$ did not diminish with repeated application over the course of an experiment (1-5 hr).

In contrast to the findings with AMPA, the current activated by the $\mathrm{GABA}_{\mathrm{A}}$ agonist muscimol $\left(I_{\text {MUSC }}\right)$ was potently depressed in the presence of $1 S, 3 R$-ACPD (Fig. $2 B$ ). As with the regulation 


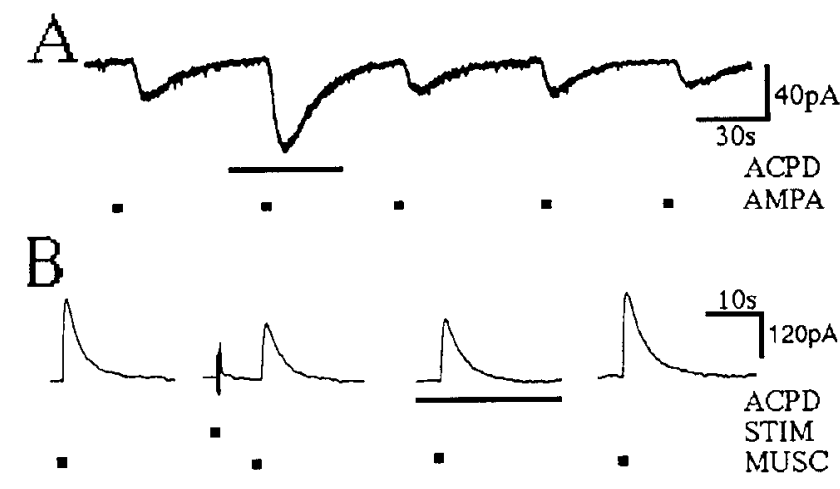

Figure 3. The potentiating effects of $1 S, 3 R$-ACPD on AMPA currents and the inhibition of muscimol currents were unaffected by intracellular dialysis with GTP- $\gamma-\mathrm{S}$. $A$, AMPA-evoked currents in an NTS neuron dialyzed with $400 \mu \mathrm{M}$ GTP- $\gamma$-S were reversibly potentiated by $20 \mu \mathrm{M}$ $1 S, 3 R$-ACPD $(A C P D)$. Currents were evoked as described in Figure 2. $B$, Muscimol (MUSC) currents were inhibited by either $100 \mu \mathrm{M} 1 S, 3 R$ ACPD $(A C P D)$ or $50 \mathrm{~Hz}(150 \mathrm{msec}, 3.2 \mathrm{~V})$ stimulation of the TS $(S T I M)$ in a neuron dialyzed with $400 \mu \mathrm{M}$ GTP- $\gamma$-S. Currents were evoked as described in Figure 2.

of $I_{\mathrm{AMPA}}$, the depression of $I_{\text {MuSC }}$ was rapid in onset, nondesensitizing, and readily reversible. In the same cell, $50 \mathrm{~Hz}$ stimulation of the TS $(100 \mathrm{msec}, 4.3 \mathrm{~V}$, in the presence of DNQX and AP5) also reduced the amplitude of the $I_{\text {Muss. }}$. In the continuous presence of $1 S, 3 R$-ACPD, no further reduction in $I_{\text {MusC }}$ was observed following an identical stimulus train. Such occlusion of the synaptically mediated depression of $I_{\text {Musc }}$ by $1 S, 3 R$ ACPD is consistent with a common mechanism being involved in the two phenomena. This would not be surprising as we have previously demonstrated (Glaum and Miller, 1992) that highfrequency stimulation of the TS can produce synaptic activation of metabotropic glutamate receptors through the release of endogenous glutamate. High-frequency stimulation of the TS inhibited $I_{\text {Musc }}$ in seven of seven neurons. In five of six cells tested, $100 \mu \mathrm{M} 1 S, 3 R$-ACPD fully occluded the ability of high-frequency stimulation to reduce $I_{\text {Musc }}$. In the other cell, high-frequency TS stimulation in the presence of $1 S, 3 R$-ACPD resulted in a further $6 \%$ decrease in $I_{\text {Musc }}$. $1 S, 3 R$-ACPD produced an identical reversible depression of $I_{\text {Musc }}$ in 13 additional cells recorded in the presence of TTX. As with $I_{\mathrm{AMPA}}$, the effects of $1 S, 3 R$-ACPD did not desensitize with continuous or repeated application over the duration of the recordings. The dose-response relationship for $1 S, 3 R$-ACPD effects on $I_{\mathrm{AMPA}}$ and $I_{\mathrm{MusC}}$ are summarized in Figure $2 C$. Based upon these observations, wc routincly employed a $100 \mu \mathrm{M}$ concentration of $1 S, 3 R$-ACPD as a supramaximal dose in all occlusion experiments. It should be noted that the effects of $1 S, 3 R-A C P D(20 \mu \mathrm{M})$ on excitatory and inhibitory transmission (Glaum and Miller, 1992) as well as on $I_{\mathrm{AMPA}}$ and $I_{\mathrm{MUSC}}$ were unaffected in the presence of L-aminophosphonopentanoic acid $(200 \mu \mathrm{M})(n=3)$, which blocks metabotropic glutamate receptor-mediated $\left[\mathrm{Ca}^{2+}\right]_{i}$ mobilization in some systems (Schoepp and Johnson, 1989). The effects of high-frequency stimulation on $I_{\text {AMPA }}$ were not examined as the results would not be readily interpretable (see Discussion).

We previously reported that $1 S, 3 R$-ACPD produced an inward current in some neurons in the dorsomedial NTS as the result of a decrease in a $\mathrm{K}^{+}$current (Glaum and Miller, 1992). High-frequency stimulation of the TS in the presence of DNQX and AP5 produced a similar inward current that was occluded by $1 S, 3 R$-ACPD. In keeping with these observations, an inward

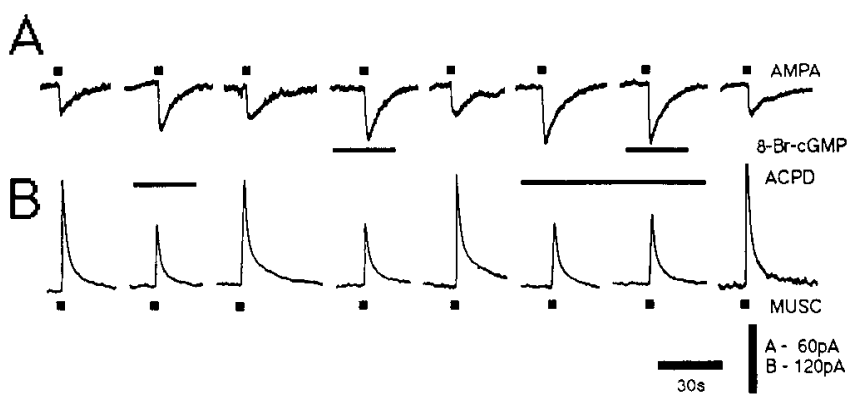

Figure 4. The cell-permeant cGMP analog 8-Br-cGMP (100 $\mu \mathrm{M})$ produccd qualitatively similar effects to those of $1 S, 3 R$-ACPD $(100 \mu \mathrm{M})$ on AMPA and muscimol currents. $A$, AMPA-evoked currents from an NTS neuron were reversibly potentiated by $1 S, 3 R-A C P D(A C P D)$ and 8-Br-cGMP. The application of 8-Br-cGMP in the presence of $1 S, 3 K-$ ACPD produced no further potentiation of the AMPA current. $B$, Qualitatively similar results on muscimol (MUSC)-evoked currents were obtained in another cell. Currents were evoked in $A$, and $B$ as described in Figure 2 and Materials and Methods; however, both AMPA and muscimol currents were evoked in the presence of $0.5 \mu \mathrm{M}$ TTX. The durations of drug applications were identical in the control and occlusion parts of the experiments shown in $A$ and $B$ as described in Materials and Methods, but are truncated in the figure.

current (5-20 pA) was observed in the present investigation in 12 of 37 cells exposed to $1 S, 3 R$-ACPD at a concentration of 25 $\mu \mathrm{M}$ or greater. Furthermore, in addition to the ability of highfrequency stimulation of the TS to reduce $I_{\text {Musc }}$, a stimulusinduced inward current was observed in five of seven cells. $1 S, 3 R$-ACPD occluded not only the stimulus-mediated reduction in $I_{\text {MusC }}$ but, in keeping with our earlier findings, it also occluded the stimulus-induced inward current. However, given the present observation that low concentrations of $1 S, 3 R$-ACPD ( $<25 \mu \mathrm{M}$; Fig. $2 C$ ) modulated $I_{\text {AMPA }}$ and $I_{\text {MusC }}$ without inducing an inward current, it seems likely that the two types of effects are unrelated. Thus, the NTS may contain several types of metabotropic glutamate receptors (Tanabe et al., 1992). Alternatively, a single type of receptor may be linked to several signal transduction events (Aramori and Nakanishi, 1992).

In order to address the question of the mechanism by which $1 S, 3 R$-ACPD modulates $I_{\mathrm{AMPA}}$ and $I_{\mathrm{Musc}}$, the effects of $1 S, 3 R$ ACPD were examined in seven cells dialyzed with GTP- $\gamma-S$. If the effects of $1 S, 3 R$-ACPD were mediated via a G-protein, dialysis with GTP- $\gamma-\mathrm{S}$ might be expected to produce irreversible effects of $1 S, 3 R$-ACPD and to occlude its subsequent actions. In this and our earlier investigations (Brooks et al., 1992), dialysis with GTP- $\gamma-S$ produced a slow outward current in NTS neurons and blocked the hypcrpolarizing effects of the GABA agonist baclofen. However, as illustrated in Figure 3, the effects of $1 S, 3 R$-ACPD on $I_{\text {MUSC }}(n=4)$ and $I_{\mathrm{AMPA}}(n=3)$ were indistinguishable from those observed in cells without added GTP$\gamma-\mathrm{S}$, suggesting that a G-protein intermediate is not an integral part of the signal transduction pathway.

The effects of $1 S, 3 R$-ACPD were neither mimicked nor blocked by the addition to the perfusate for $8 \mathrm{~min}$ of phorbol myristate acetate $(20 \mu \mathrm{M} ; n=3)$, arachidonic acid (100 $\mu \mathrm{M} ; n$ $=3$ ), or sodium nitroprusside $(200 \mu \mathrm{M} ; n=3)$.

Recently, Lewis et al. (1991) have provided evidence that activation of guanylate cyclase may play a role in the processing of afferent baroreceptor information at the level of the NTS. We therefore examined the effects of a cell-permeant form of cGMP on $I_{\mathrm{AMPA}}$ and $I_{\mathrm{MUSC}}$. As illustrated in Figure 4, addition of $100 \mu \mathrm{M} 8$-Br-cGMP reversibly potentiated $I_{\mathrm{AMPA}}(123 \pm 6.2 \%$ 
of control, $n=9)$ and depressed $I_{\text {MusC }}(75.0 \pm 4.1 \%$ of control, $n=5)$ in a similar fashion to $1 S, 3 R$-ACPD $(128.7 \pm 7.2 \%$ and $77.9 \pm 3.4 \%$ of control, respectively). We then performed occlusion experiments to compare the effects of $1 S, 3 R$-ACPD and 8-Br-cGMP when separately and coapplied. $1 S, 3 R$-ACPD $(100$ $\mu \mathrm{M})$ or 8 -Br-cGMP $(100 \mu \mathrm{M})$ potentiated $I_{\mathrm{AMPA}}$ to a similar extent when applied separately $(134.6 \pm 8.6 \%$ and $130.9 \pm 9.4 \%$ of control, respectively) or when coapplied $(131.6 \pm 10.6 \%$ of control, $n=4)$. Similar results were obtained in experiments examining inhibition of $I_{\text {MusC }}(1 S, 3 R$-ACPD alone, $83.7 \pm 3.3 \%$; 8-Br-cGMP, $80.3 \pm 2.3 \%$; coapplication, $78.6 \pm 5.9 \%$ of control; $n=5$ ). The effect of 8-Br-cGMP was also compared to the cell-permeant cAMP analog dibutryl-cAMP $(100 \mu \mathrm{M})$. In three of four cells, dibutryl-cAMP produced no discernable effect on $I_{\mathrm{AMPA}}$ or $I_{\mathrm{MUSC}}$. However, in one cell, $I_{\mathrm{AMPA}}$ was reduced to $83.3 \%$ of control, an effect opposite to that produced by $1 S, 3 R$-ACPD or 8-Br-cGMP.

Endogenous G-protein-independent activators of guanylate cyclase such as brain-derived natriuretic peptide (BNP) (Chang et al., 1989; Ermirio et al., 1989; Lewis et al., 1991) are found in the NTS (Standaert et al., 1986) and appear to be colocalized with glutamate in peripheral afferent projections to the NTS (K. Hurley, personal communication). In order to examine further the potential role of CGMP, we next examined the effects of exogenous BNP $(3 \mu \mathrm{M})$ on $I_{\mathrm{AMPA}}$ and $I_{\mathrm{MUSC}}$. As illustrated in Figure 5, BNP produced qualitatively similar effects on $I_{\text {AMPA }}$ $(122.7 \pm 1.0 \%$ of control, $n=3)$ and $I_{\text {MusC }}(80.6 \pm 11.4 \%$ of control, $n=4)$ compared with those produced by $1 S, 3 R$-ACPD $(25 \mu \mathrm{M})(119.0 \pm 3.0 \%$ and $81.2 \pm 7.1 \%$ of control, respectively) in the same group of cells. Although rapid in onset, the effects of BNP differed from those of $1 S, 3 R$-ACPD in two notable ways. Recovery of $I_{\mathrm{AMPA}}$ or $I_{\mathrm{MUSC}}$ to control levels following washout of BNP was much more prolonged than that following $1 S, 3 R$-ACPD, requiring up to $20 \mathrm{~min}$. Further addition of the peptide within $30 \mathrm{~min}$ of the initial application failed to affect AMPA or muscimol currents $(n=6)$. Notably, $1 S, 3 R$-ACPD applied during this period of BNP desensitization (either alone or in the presence of BNP) was fully effective in five of six cells at potentiating $I_{\mathrm{AMPA}}$ or reducing $I_{\mathrm{MUSC}}$, indicating an absence of heterologous desensitization.

\section{Discussion}

Metabotropic glutamate receptors represent a large family of related proteins that are linked to several signal transduction systems (Aramori and Nakananishi, 1992; Tanabe et al., 1992). Initially, activation of metabotropic glutamate receptors was shown to produce mobilization of $\mathrm{Ca}^{2+}$ from intracellular stores in neurons and glia through an inositol trisphosphate-mediated mechanism (Murphy and Miller, 1988; Ambrosini and Meldolesi, 1989; Palmer et al., 1989; Glaum et al., 1990; Manzoniet et al., 1990). More recently, inhibition of adenylate cyclase (Cartmell et al., 1992; Schoepp et al., 1992; Tanabe et al., 1992), $\mathrm{K}^{+}$(Charpak et al., 1990; Desai and Conn, 1991; McCormick and Von Krosigk, 1992), and $\mathrm{Ca}^{2+}$ conductances (Sahara and Westbrook, 1991; Swartz and Bean, 1992) have been demonstrated. Importantly, the signal transduction systems linked to some types of metabotropic glutamate receptors have not yet been identified (Lovinger, 1991; Tanabe et al., 1992). Metabotropic glutamate receptors have recently been shown to potentiate ionotropic glutamate responses in several parts of the brain (Aniksztejn et al., 1991; Harvey et al., 1991; Bleakman et al., 1992; Glaum et al., 1992; Kinney and Slater, 1992). In
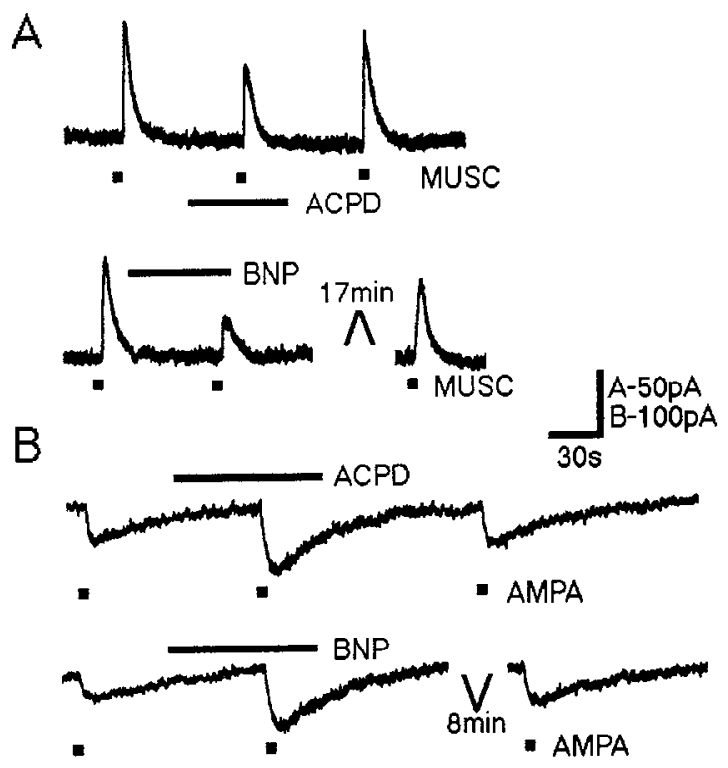

Figure 5. Addition to the bath of BNP $(3 \mu \mathrm{M})$ produced qualitatively similar effects to those of $1 S, 3 R$-ACPD $(25 \mu \mathrm{M})$ on AMPA and muscimol (MUSC) currents. $A$, The muscimol current from an NTS neuron was reversibly reduced by bath-applied $1 S, 3 R-A C P D(A C P D)$. BNP similarly reduced the muscimol current. However, recovery to control levels required approximately $17 \mathrm{~min}$ of washing. $B, 1 S, 3 R$-ACPD and BNP similarly enhanced AMPA currents. As in $A$, recovery from BNP was far slower than that of $1 S, 3 R$-ACPD. Currents in $A$ and $B$ were evoked in the presence of TTX $(0.5 \mu \mathrm{M})$ and glutamate or GABA receptor antagonists, as described in Materials and Methods.

the dorsal horn of the spinal cord, this effect of $1 S, 3 R-\mathrm{ACPD}$ is clearly independent of a change in $\left[\mathrm{Ca}^{2+}\right]_{i}$ (Bleakman et al., 1992). We have now demonstrated that $1 S, 3 R$-ACPD can also modulate postsynaptic receptors for AMPA and GABA in the NTS and in the latter case that these effects are mimicked by endogenously released transmitter.

Our previous experiments demonstrated that $1 S, 3 R$-ACPD produced potent inhibition of pharmacologically isolated EPSCs and IPSCs evoked by electrical stimulation in the region of the TS in the dorsomedial subdivision of the NTS (Glaum and Miller, 1992). We also observed direct postsynaptic excitatory effects of $1 S, 3 R$-ACPD on some NTS neurons that could be mimicked by high-frequency stimulation of the TS in the presence of ionotropic glutamate receptor antagonists. This inward current evoked by TS stimulation was indistinguishable from that produced by $1 S, 3 R$-ACPD. These excitatory effects of $1 S, 3 R$-ACPD appeared to be unrelated to mobilization of $\left[\mathrm{Ca}^{2+}\right]_{i}$ as assessed by microfluorometric techniques. In the present investigation, $1 S, 3 R$-ACPD and TS stimulation produced both direct current responses and, even more notably, inhibition of $I_{\text {Musc }}$ even though neurons were dialyzed with EGTA. $1 S, 3 R$ ACPD also modulated $I_{\mathrm{AMPA}}$ in neurons dialyzed with EGTA. In both instances, concentrations of $1 S, 3 R$-ACPD that failed to produce detectable $\left[\mathrm{Ca}^{2+}\right]_{i}$ changes in fura-2-loaded cells recorded under voltage clamp (Glaum and Miller, 1992) produced profound changes in AMPA and muscimol currents. Thus, although undetectable changes in $\left[\mathrm{Ca}^{2+}\right]_{i}$ in distal processes could contribute to the observed effects of $1 S, 3 R$-ACPD, observations to date argue against this hypothesis. In contrast with the effects on $I_{\text {Musc }}$, the effects of high-frequency TS stimulation on $I_{\text {AMPA }}$ were not readily determinable using the present paradigm, as the sensitivity of AMPA receptors may be variably decreased 
by synaptically released glutamate through a process of homologous desensitization.

How, then, are the effects of $1 S, 3 R$-ACPD on $I_{\mathrm{AMPA}}$ and $I_{\mathrm{MUSC}}$ produced? We noted that a cell-permeant cGMP analog produced effects that were qualitatively similar to those of $1 S, 3 R$ ACPD on $I_{\mathrm{AMPA}}$ and $I_{\mathrm{MUSC}}$. While the lack of effect of sodium nitroprusside appears to suggest that a $1 S, 3 R$-ACPD-mediated activation of guanylate cyclase by a nitric oxide (NO)-dependent mechanism does not play a role in mediating $1 S, 3 R$-ACPD's effects, this hypothesis remains attractive for a number of reasons. For example, NO synthase is found widely in the NTS (Vincent and Kimura, 1992). There is also no direct evidence demonstrating that sodium nitroprusside actually generates sufficient NO within the NTS to activate guanylate cyclase. Indeed, Lcwis et al. (1991) have demonstrated that while sodium nitroprusside failed to activate soluble guanylate cyclase in the NTS, activation of this enzyme by $s$-nitrosocysteine could regulate the processing of baroreceptor afferent transmission. Alternatively, $1 S, 3 R$-ACPD may generate another diffusible activator of guanylate cyclase such as CO (Marks et al., 1991).

In addition to NO-mediated activation, $\mathrm{Ca}^{2+}$ and $\mathrm{G}$-proteinindependent activation of guanylate cyclase can be produced by atrial natriuretic peptide (ANP) and/or the related BNP (Chang et al., 1989; Ermirio et al., 1989; Lewis et al., 1991). The NTS contains both ANP, derived from projections from the hypothalamus, and BNP, which is found in afferent projections to the NTS from the nodose ganglia (Standaert et al., 1986; Hurley, personal communication). Exogenous glutamate or activation of baroreceptor afferents has been shown to potentiate the effects of ANP within the NTS (McKitrick and Calaresu, 1989). Thus, it is possible that the effects of $1 S, 3 R-\mathrm{ACPD}$ are mediated by release of a BNP-like peptide within the NTS. Indeed, exogenous BNP produces effects that are qualitatively similar to those of $1 S, 3 R$-ACPD. Both compounds produce a rapid potentiation of $I_{\mathrm{AMPA}}$ and reduction of $I_{\mathrm{MUSC}}$. The slower kinetics of recovery from and desensitization to BNP's effects may reflect difficulty in washing this large peptide out of the slice following bath application. However, our data suggest that it is unlikely that the effects of $1 S, 3 R$-ACPD are mediated by release of BNP as the effects of $1 S, 3 R$-ACPD were preserved when those of BNP were completely desensitized. The apparent similarities between the effects of BNP and $1 S, 3 R$-ACPD suggest that they may be working through parallel, cGMP-utilizing pathways, albeit via different receptors. While it would be useful to examine the effects of selective $1 S, 3 R$-ACPD and BNP receptor or cGMPdependent kinase antagonists, no such compounds are widely available at present.

Although a cGMP-mediated mechanism appears to be the most likely candidate underlying $1 S, 3 R$-ACPD's effects in the NTS, $1 S, 3 R$-ACPD and glutamate could also directly modulate kainate/AMPA and $\mathrm{GABA}_{\mathrm{A}}$ receptors in these neurons. This could be achieved by occupancy of an allosteric site to affect agonist binding or channel activity. Indeed, regulation of GA$\mathrm{BA}_{\mathrm{A}}$ receptors by a glutamate allosteric site has been previously suggested (Stelzer and Wong, 1989). As the exploration of these possibilities is beyond the resolution of the whole-cell patch slice technique, we are currently exploring the effects of $1 S, 3 R$ ACPD on AMPA and GABA A $_{A}$ channels in excised patch recordings from neurons dissociated from this region of the NTS. This may also provide further insight into the role of soluble guanylate cyclase in the $1 S, 3 R$-ACPD responses.

Finally, although changes in input resistance of the neuron beyond the detection level of the recording method could result in a small change in sensitivity to AMPA or muscimol, the magnitude and opposing nature of $1 S, 3 R$-ACPD effects on these currents argue against this hypothesis. The involvement of the adenylate cyclase system can also be ruled out by the failure of a cAMP analog to mimic or block the effects of $1 S, 3 R$-ACPD. The negative results with arachidonic acid and the apparent independence of the effects from changes in $\left[\mathrm{Ca}^{2+}\right]_{i}$ suggest that products of phospholipid metabolism are also unlikely to mediate the observed actions of $1 S, 3 R$-ACPD.

The ability to evoke both postsynaptic $1 S, 3 R$-ACPD-like currents and modulatory effects on GABA receptors by physiologically relevant levels of TS stimulation is intriguing. Our data suggest that synaptically released glutamate acting at $1 S, 3 R$ $A C P D$ receptors may, under increasing levels of barorcceptor activation, provide a positive feedforward mechanism to increase the overall synaptic afferent transmission in the NTS. The postsynaptic inhibition of $I_{\text {MusC }}$ may explain the potent ability of $1 S, 3 R$-ACPD to decrease IPSCs evoked by stimulation in the region of the TS. Conversely, according to our previous observations, $1 S, 3 R$-ACPD inhibits EPSCs far less efficiently (Glaum and Miller, 1992). These data suggest that $1 S, 3 R$ ACPD inhibition of EPSCs may be the result of presynaptic inhibition of glutamate release. What glutamate is released, however, may be acting on sensitized postsynaptic ionotropic glutamate receptors. Thus, activation of postsynaptic metabotropic receptors may counteract the tendency of AMPA receptors to undergo desensitization. Furthermore, given that inhibitory GABAergic interneurons in the vicinity of the TS appear to be driven largely by excitatory synaptic inputs (Miles, 1987; Brooks et al., 1992), the net outcome of metabotropic receptor activation would be predicted to be largely excitatory. Thus, intrinsic neurons of the NTS would exhibit increased excitability via (1) a direct depolarizing influence of metabotropic receptor occupation, (2) an increased sensitivity of the AMPA subtype of ionotropic glutamate receptor, and (3) a decreased sensitivity to the inhibitory effects of synaptically released GABA. These actions may serve to potentiate vagal afferent transmission under conditions of increased baroreceptor activation and thus enhance descending bradycardic influences on the heart.

\section{References}

Ambrosini A, Meldolesi J (1989) Muscarinic and quisqualate receptorinduced phosphoinositide hydrolysis in primary cultures of striatal and hippocampal neurons. Evidence for differential mechanisms of activation. J Neurochem 53:825-833.

Aniksztejn L, Bregestovski P, Ben-Ari Y (1991) Selective activation of quisqualate metabotropic receptor potentiates NMDA but not AMPA responses. Eur J Pharmacol 205:327-328.

Aramori I, Nakanishi S (1992) Signal transduction and pharmacological characteristics of a metabotropic glutamate receptor, mGluR1, in transfected CHO cells. Neuron 8:757-765.

Bleakman D, Rusin KI, Chard PS, Glaum SR, Miller RJ (1992) Metabotropic glutamate receptors potentiate ionotropic glutamate responses in the rat dorsal horn. Mol Pharmacol 42:192-196.

Brooks PA, Glaum SR, Miller RJ, Spyer KM (1992) The actions of baclofen on neurones and synaptic transmission in the nucleus tractus solitarii of the rat in vitro. J Physiol (Lond) 457:115-129.

Cartmell J, Kemp JA, Alexander SPH, Hill ST, Kendall DA (1992) Inhibition of forskolin stimulated cyclic AMP formation by 1-aminocyclopentane-trans-1,3, dicarboxylate in guinea-pig cerebral cortical slices. J Neurochem 58:1964-1966.

Champagnat J, Siggins GR, Koda LY, Denavit-Saubie M (1985) Synaptic responses of neurons of the nucleus tractus solitarius in vitro. Brain Res 325:49-56.

Chang M-S, Lowe DG, Lewis M, Hellmiss R, Chen E, Goeddel D 
(1989) Differential activation by atrial and brain natriuretic peptides of two different receptor guanylate cyclases. Nature 341:68-72.

Charpak S, Gähwiler BH, Dok Q, Knopfel T (1990) Potassium conductances in hippocampal neurons blocked by excitatory amino acid transmitters. Nature 347:765-767.

Desai MA, Conn PJ (1991) Excitatory effects of ACPD receptor activation in the hippocampus are mediated by direct effects on pyramidal cells and blockade of synaptic inhibition. J Neurophysiol 66: $40-52$.

Donoghue S, Felder RB, Gilbey MP, Jordan D, Spyer KM (1985) Postsynaptic activity evoked in the nucleus tractus solitarius by carotid sinus and aortic nerve afferents in the cat. J Physiol (Lond) 360:261273.

Drewe JA, Miles R, Kunze DL (1990) Excitatory amino acid receptors of guinea pig medial nucleus tractus solitarius neurons. Am J Physiol 259:1389-1395.

Ermirio R, Ruggeri P, Cogo CE, Molinari C, Calaresu FR (1989) Neuronal and cardiovascular responses to ANF microinjected into the solitary nucleus. Am J Physiol 256:R577-R582.

Glaum SR, Miller RJ (1992) Metabotropic glutamate receptors mediate excitatory transmission in the nucleus of the solitary tract. $J$ Neurosci 12:2251-2258.

Glaum SR, Holzwarth J, Miller RJ (1990) Metabotropic glutamate receptors activate $\mathrm{Ca}^{2+}$ mobilization and $\mathrm{Ca}^{2+}$ influx in astroglial cells. Proc Natl Acad Sci USA 87:3454-3458.

Glaum SR, Brooks PA, Miller RJ (1993) Activation of metabotropic glutamate receptors depresses muscimol-but not AMPA-evoked currents in the nucleus tractus solitarius (NTS) of the rat in vitro. J Physiol (Lond), in press.

Glaum SR, Slater NT, Rossi DJ, Miller RJ (1992) The role of metabotropic glutamate (ACPD) receptors at the parallel fiber-Purkinje cell synapse. J Neurophysiol 68:1453-1462.

Harvey J, Frenguelli BG, Sunter DC, Watkins JC, Collingridge GL (1991) The actions of $1 S, 3 R-A C P D$, a glutamate metabotropic receptor agonist, in area CAl of rat hippocampus. $\mathrm{Br} \mathrm{J}$ Pharmacol 104: C79.

Kinney GA, Slater TN (1992) Potentiation of mossy fibre evoked EPSP's in turtle cerebellar Purkinje cells by the metabotropic glutamate receptor agonist (1S,3R-ACPD). J Neurophysiol 67:1006-1008.

Leone C, Gordon FJ (1989) Is L-glutamate a neurotransmitter of baroreceptor information in the nucleus of the tractus solitarius? J Pharmacol Exp Ther 250:953-962.

Lewis SL, Machado BH, Ohta H, Talman WT (1991) Processing of cardiopulmonary afferent input with the nucleus tractus solitarii involves activation of soluble guanylatc cyclase. Eur J Pharmacol 203: 327-328.

Lovinger DM (1991) trans-ACPD decreases synaptic excitation in rat striatal slices through a presynaptic action. Neurosci Lett 129:17-21

Manzoni O, Fagni L, Pin J-P, Rassendren F, Poulat F, Sladeczek F, Bockaert J (1990) (Trans)-1-amino-cyclopentyl-1,3-dicarboxylate stimulates quisqualate phosphoinositide-coupled receptors but not ionotropic glutamate receptors in striatal neurons and Xenopus oocytes. Mol Pharmacol 38:1-6.

Marks GS, Bricn JF, Nakatsu K, McLaughlin BF (1991) Docs carbon monoxide have a physiological function. Trends Pharmacol Sci 12: $185-188$.

McCormick DA, Von Krosigk M (1992) Corticothalamic activation modulates thalamic firing through glutamate "metabotropic" receptors. Proc Natl Acad Sci USA 89:2774-2778.

McKitrick DJ, Calaresu FR (1989) Baroreceptor activation or glutamate coinjection facilitates depressor responses to ANF microinjected into NTS. Am J Physiol 257:R405-R409.

Meeley MP, Underwood MD, Talman WT, Reis DJ (1989) Content and in vitro release of endogenous amino acids in the area of the nucleus of the solitary tract of the rat. J Neurochem 53:1807-1817.

Mifflin SW, Felder RB (1990) Synaptic mechanisms regulating cardiovascular afferent inputs to solitary tract nucleus. Am J Physiol 28: 653-661.

Miles R (1987) Frequency dependence of synaptic transmission in nucleus of the solitary tract in vitro. J Neurophysiol 55:1076-1090.

Miller RJ (1991) Metabotropic excitatory amino acid receptors reveal their true colors. Trends Pharmacol Sci 12:365-367.

Murphy SN, Miller RJ (1988) A glutamate receptor regulates $\mathrm{Ca}^{2+}$ mobilization in hippocampal neurons. Proc Natl Acad Sci USA 85: 8732-8741.

Palmer E, Monaghan DT, Cotman CW (1989) Trans-ACPD, a selective agonist of the phosphoinositide-coupled excitatory amino acid receptor. Eur J Pharmacol 166:585-587.

Pawloski-Dahm C, Gordon FJ (1992) Evidence for a kynurenateinsensitive glutamate receptor in the nucleus tractus solitarius. Am J Physiol 363:1611-1615.

Sahara Y, Wcstbrook GL (1991) Trans-ACPD blocks high threshold calcium currents on cultured hippocampal neurons. Soc Neurosci Abstr 17:1168.

Schoepp DD, Johnson BG (1989) Inhibition of excitatory amino acidstimulated phosphoinositide hydrolysis in the neonatal rat hippocampus by 2-amino-3-phophonopropionate. J Neurochem 53:1865-1868.

Schoepp DD, Johnson BG, Monn JA (1992) Inhibition of cAMP formation by a selective metabotropic glutamate receptor agonist. J Neurochem 58:1184-1186.

Standaert DH, Needleman P, Saper C (1986) Organization of atriopeptin-like immunoreactive neurons in the central nervous system of the rat. J Comp Neurol 253:315-341.

Stelzer A, Wong RKS (1989) GABA-A responses in hippocampal neurons are potentiated by glutamate. Nature 337:170-173.

Swartz KJ, Bean BP (1992) Rapid and reversible suppression of voltage-gated calcium channels by a metabotropic glutamate receptor in hippocampal pyramidal neurons. Biophys J 61:A249.

Tanabe Y, Masu M, Ishii T, Shigemoto R, Nakanishi S (1992) A family of metabotropic glutamate receptors. Neuron 8:169-179.

Vincent SR, Kimura H (1992) Histochemical mapping of nitric oxide synthase in the rat brain. Neuroscience 46:755-784. 